\title{
ON THE PROGRESS OF THE CONSTRUCTION OF THE SUKHAREV MERIDIAN AUTOMATIC HORIZONTAL INSTRUMENT (MAHIS)
}

\author{
R.I. GUMEROV ${ }^{2}$, V.B. KAPKOV ${ }^{2}$, T.R. KIRIAN ${ }^{1}$, N.S. LIADOVOI ${ }^{3}$, G.I. PINIGIN ${ }^{3}$, \\ A.A. POZHALOV ${ }^{3}$, V.P. SIBILEV ${ }^{3}$, A.W. SCHUMACHER ${ }^{1}$, N.A. SHKUTOVA ${ }^{1}$, \\ AND O.E. SHORNIKOV ${ }^{3}$ \\ 1 Central Astronomical Observatory (Pulkovo) \\ 196140 Leningrad, USSR \\ 2 Engelhardt Astronomical Observatory \\ 422526 Kazan, USSR \\ ${ }^{3}$ Nikolaev Branch, Pulkovo Observatory \\ 327030 Nikolaev, USSR
}

\begin{abstract}
The MAHIS is the L.A. Sukharev meridian automatic horizontal instrument. It has all the advantages of the Pulkovo HMC and is devoid, or nearly devoid, of its disadvantages. A scheme of the MAHIS includes a flat mirror of $D=300 \mathrm{~mm}$ and two immovable horizontal tubes of $\mathrm{D}=190 \mathrm{~mm}$, focal length 8000 $\mathrm{mm}$. There is a pavilion for the central unit and 2 roofed pavilions for eyepiece parts of the tubes. The MAHIS is provided with an automatic registering device, a system for meteorological data collection, and is computer controlled. The work on this telescope is being carried out at the Pulkovo, Kazan and Nikolaev observatories. The expected precision of the instrument is \pm 0 ".05 in both coordinates with respect to systematic errors.
\end{abstract}

The Sukharev meridian automatic horizontal instrument (MAHIS) is intended for the determination of coordinates of celestial bodies: stars to 13th magnitude, planets and minor planets, star-like and disk-like objects. Photometry of celestial bodies to an accuracy of 0.05 , observations in different wavelength regions, and study of refraction can be performed with the use of MAHIS.

The design of the MAHIS is based on the Pulkovo HMC (Gumerov et al. 1986; Gumerov, Kapkov et al. 1987; Sukharev 1948). The essential part of the MAHIS is a monolithic flat mirror with an axis and the diameter of $300 \mathrm{~mm}$. On both sides of the mirror graduated circles with a diameter of 412 $\mathrm{mm}$ and gears for setting the system are fixed. The automatic reading system of the divided circle consists of four photoelectric microscopes. Two additional microscopes are mounted for a study of division errors. The automatic setting system of the mirror along the zenith distance has two velocities of rotation: $10^{\circ} / \mathrm{sec}$ and $1 \mathrm{arcmin} / \mathrm{sec}$, with a precision of setting of $\pm 2 "$. The mirror can be elevated with a special elevator - a counterpoise device meant to direct the horizontal tubes to each other. The position of the vertical line will be determined with the artificial horizons in nadir and zenith, with an accuracy of 0."01 to 0.02. MAHIS will be equipped with two vacuum immovable horizontal tubes (objective diameters of $190 \mathrm{~mm}$, focal lengths $8000 \mathrm{~mm}$ ). Star transit recording is made with the eyepiece photoelectric micrometer with an active analyser. The latter is a grid with a system of lambda-like slits. The time of registration can vary from $20 \mathrm{sec}$ (for bright stars and lightmarks) to $90 \mathrm{sec}$ (for faint stars). 
Computer control of the MAHIS makes it possible to realize two modes of star observations: semiautomatic control with the use of an observer for experimental observations and investigations, and automatic control for observations reduction and derivation of highly precise coordinates of a great number of stars.

There is a pavilion for the central unit and two roofed pavilions for eyepiece parts of the horizontal tubes. The observer and electronic facilities should be located in a separate room at a distance from the MAHIS.

The methods of investigations of the MAHIS are the same as for the automatic Puolkovo HMC (Gumerov et al. 1987a, 1987b; Pinigin 1976). It includes the determination and control of the variation of the instrumental parameters during star observation (viz., the mirror azimuth relative to the horizontal tubes, the mirror tilt, the zero-point of the divided circle and the tube inclinations), collection of the meterological data and measurement of the temperature in the pavilion and instrument. The computer control allows one to include studies of the divided circle division errors, the pivot errors and the irregularities of the form of the relecting mirror's surface.

MAHIS enables not only the determination of differential coordinates of celestial bodies, but also the determination of absolute coordinates. For this purpose it is possible to determine a position of the divided circle relative to the vertical line with an artificial horizon, to receive a stable orientation of the two long-focus horizontal tubes as azimuth marks and to observe planets and minor planets (only at night). The expected precision of the MAHIS is 0.05 in both coordinates with respect to systematic errors.

The observing program for MAHIS incorporates FK5 stars, IRS and other programs for the purpose of the derivation of a high accuracy star reference frame, of the determination of the interconnection between radio reference frame and optical reference frame and others. Simultaneous observations are planned to be made with two MAHIS' in the northern and southern hemispheres.

From the beginning of 1988 the design and model of some parts of the MAHIS and its electronic accessories have been elaborated.

\section{References}

Gumerov, R., Kapkov, V., and Pinigin, G.: 1986, "Automatic horizontal meridian circle at Pulkovo", in Astrometric Techniques, IAU Symposium 109, H. Eichhom and R.J. Leacock (eds.), D. Reidel, Dordrecht, p. 206.

Gumerov, R., Kapkov, V., Kirian, T., and Pinigin, G.: 1987, "Potential of the computer controlled horizontal meridian circle at Pulkovo", in Bull. Obs. Astron. Belgrade, 137, 30.

Gumerov, R., Kirian, T., and Pinigin, G.: 1987a, Opredelenie popravok diametrov Pulkovskogo gorizontalnogo meridianogo kruga L.A. Sukhareva", in Sovremenaja Astrometrija, Akad. Nauk SSSR, Leningrad, p. 70 (in Russian).

Gumerov, R., Kirian, T., Korepanov, V., and Pinigin, G.: 1987b, “O sisteme skloneij gorizontalnogo meridianogo kruga Pulkovskoj observatorii”, in Sovremenaja Astrometrija, Akad. Nauk SSSR, Leningrad, p. 256 (in Russian).

Pinigin, G.: 1976 , "The results of determination of R.A. of 188 stars with $-10^{\circ}$ to $+86^{\circ}$ declination as obtained from observations with the Sukharev Horizontal Meridian Circle", in Izv. GAO, Nauka, Leningad, p. 105 (in Russian).

Sukharev, L.: 1948 , "K voprosu o prinzipialnih preimushestvah i konstruktivnih osobenostjah horizontalnogo meridianogo instrumenta", in Astron. Zhurnal 25, No. 1, 59 (in Russian). 